\title{
Performance Appraisal of Faculty Members Based on Internal Quality Assurance System: A Delphi Study
}

\author{
Ahmed Khtere ${ }^{1}$ \\ ${ }^{1}$ College of Education, Fayoum University, Fayoum, Egypt \\ Correspondence: Ahmed Khtere, College of Education, Fayoum University, Fayoum, 63514, Egypt.
}

Received: August 2, 2020

Accepted: August 27, 2020

Online Published: August 28, 2020

doi:10.5430/ijhe.v9n6p87

URL: https://doi.org/10.5430/ijhe.v9n6p87

\begin{abstract}
Performance Appraisal (PA) aimed at faculty staff puts emphasis on several teaching, research, and administration duties. The educational institutions seek to adopt a systematic assessment of faculty performance according to the institutional quality system. The study argues that PA can be developed by Entrustable Professional Activities (EPAs) which determinate the competences of faculty through the processes of internal quality assurance (IQA). This study establishes consensus, by using Delphi study, among experts on performance appraisal tools, and aims to provide a framework for EPAs which can be listed to analyse the faculty roles. During three rounds of the Delphi process, 29 experts reported four main roles of faculty in IQA namely, instructor, planner, assessor, and mentor. Participants developed 18 tools can be used to assess 14 EPAs to demonstrate the necessary competences to execute these activities unsupervised. The results can demonstrate the competences to execute these activities unsupervised.
\end{abstract}

Keywords: performance appraisal, entrustable professional activities, internal quality assurance, faculty development

\section{Introduction}

Performance appraisal has become one of the essential practices in the management of diverse organizations. As aptly put by Fletcher, 'PA [performance appraisal] has become a general heading for a variety of activities through which organizations seek to assess employees and develop their competence, enhance performance and distribute rewards' (p. 473). In the higher education sector, carrying out staff performance assessment regularly is commonly dictated by the need for greater accountability as necessitated by the educational institutions. Hence, formulating and implementing a proper scheme that is aimed at measuring staff performance in an educational institution is intended not only as a response to this requirement but also as a managerial policy mechanism whose would be to achieve educational efficiency that has the potential to impact positively on the teaching and learning process.

Many researchers refer to the goal of a great appraisal system is for professional development, it is not about the ranking or grading of teachers nor the weeding out of poor teachers, it is to create an environment where everyone is used to the best of their abilities (Bradley, 1992). Within this context, the best using of abilities is also an objective of internal quality assurance systems which is expected to improve the institutions' core missions and its staff roles namely, teaching and learning, research and activities related to community engagement (Tavares et al., 2018). Moreover, the higher education institutions have had to define how IQA practices and faculty effects are perceived within academia and how it may be helpful to critically reflect on how their practices can be more effective and aligned with academia's expectations (Cardoso et al., 2019).

As a program initiated and developed by Imam Abd-Elrahman University (IAEU), The Program of Quality Assurance Dashboard (PQAD) is meant to 'monitor and enhance the teaching and learning processes' within the University various academic structures (VP for Academic Affairs/Academic Initiatives Directorate, n.d.). PQAD concerned with promoting and sustaining high quality in the daily academic processes by ensuring compliance with five established dimensions namely, learning outcomes, teaching \&learning, assessment, students support, and faculty development. This was piloted through all courses within the foundation year for the last four academic years. The program put forward an academic program contents number of processes, reflecting the type of actions to be carried out at various stages namely, initiation, planning, execution, monitoring and controlling, and closing. The emphasis here is exclusively on individual performance. Higher education institutions, like any other organizations, highly rely on their personnel, be they academic or support staff, to meet their goals, to deliver the products and 
services they specialize in, and finally to achieve competitive advantage' (Sonnentag \& Frese, 2002).

Generally, there are two dimensions to the concept: individual behaviour (action) and its related outcome. In the context of higher education, the behavioural dimension involves the tasks entrusted to a member of staff, the most significant of which include teaching, research, and administrative duties. Yet it is the outcome resulting from this behavioural aspect that is the primary focus of any undertaking intended to measure/review performance at the individual level. It is worth noting that there is an array of expressions utilized to designate the process of evaluating the performance of individuals, for instance, one can cite performance appraisal, performance review, performance assessment, performance evaluation, performance measurement, performance management and so forth. In addition to this variety in the terminology used, there are also different definitions that attempted to shed light on the concept of performance appraisal. Considered as 'the most crucial phase of the performance management process' (Deb, 2006), this concept consists of two-word conjunction, 'performance' and 'appraisal'. In view of that, Deb defines the term 'performance' as 'what is expected to be delivered by an individual or a set of individuals within a time frame', and the term 'appraisal' as 'the evaluation of worth, quality or merit'.

The present study seeks to analyze the roles of PYP staff according to PQAD processes as a part of an evaluation scheme aimed at measuring teaching staff performance based on internal quality assurance systems by using the expected skill sets or entrustable professional activities (EPAs) from faculty members. Given its purpose, the study starts with a background, which presents the reasons commonly adduced to justify the conduct of regular performance evaluation, and briefly illustrates aspects of its modus operandi through instances derived from the higher education sectors in some universities. Moreover, it sets out to elucidate the meaning of several research-related concepts along with a review of some perspectives on performance appraisal in the existing literature. Finally, the study attempts made at formulating and suggesting an initial scheme for staff performance appraisal based on their roles of PQAD approaches and domains. Paragraph: use this for the first paragraph in a section, or to continue after an extract.

\subsection{Reasons for Evaluation}

Designing and implementing a performance appraisal system within an educational institution requires the determination of clearly defined motives justifying the establishment of such a scheme. According to Galle (2009), three principal reasons are vindicating the recourse to an evaluation system: a) improvement of teaching performance, b) making personnel decisions, and c) provision of information to various bodies, whether government agencies or accredited institutions. In a more-or-less similar vein, other authors, such as Marsh (1987) and Richardson (2005), consider that the drives behind staff performance assessment involve, amongst other things, the provision of feedback that is intended to enhance teaching practice and allow the relevant administration to take the measures it deems necessary.

In this context, scholars have put forward various definitions of performance appraisal. By way of illustration, and in order to grasp the meaning of the concept under consideration. Bartol and Martin referred to performance appraisal is the process of defining expectations for staff performance; measuring employee performance relative to those expectations; and giving feedback to them (Bartol \& Martin, 1998). A different perspective, in the financial sector, ensured that PA is an on-going systematic evaluation of how well an individual is carrying out the duties of his/her current tasks, it predictably contains an assessment of the staff need or potential for further development (Caruth et al., 2008). But Schuler and others, in an early study, emphasized that it is a formal structured system of measuring and evaluating an employee's job-related behaviour and outcomes to discover how and why the employee is presently performing on the job and how the employee can perform more effectively in the future so that the employee, organization, and society will benefit (Schuler et al., 1989). Mathis and Jackson discussed that it is the process of determining how well employees do their job relative to a standard and communicating that information to the employee (Mathis \& Jackson, 2008).

Closer scrutiny of this sample of definitions reveals that, overall, the focus is on two main elements: measuring the employee's performance in their job and linking this performance to the likelihood of further professional development. Additionally, it seems clear that performance appraisal is used in a variety of contexts, this obviously includes the educational sector where the process is regularly undertaken with a view to promoting efficiency in teaching and learning. The faculty evaluation process is defined by Rector as the systematic approach that an institution uses to determine if faculty members are being successful in meeting the performance criteria set forth by the institution (Rector, 2009).

By and large, measuring staff performance within the higher education sector has witnessed a rapid proliferation in recent decades. The performance appraisal schemes adopted by various educational institutions tend to be more Published by Sciedu Press 
customized to the specific contexts in which they are implemented. In other words, there is a diversity of evaluation systems that, in actual fact, reflect the proper circumstances and priorities of each educational organization. In addition, it is worth mentioning that western educational institutions have acquired greater experience in this regard. Some performance indicators were highlighted as important factors that have a direct bearing on the educational profile of higher education institutions, for instance, these are an attraction of research funds, papers at conferences, publications by staff and citations, patents/inventions/consultancies, teaching quality, to name but a few. Nevertheless, it was until 1987 that universities made the commitment to systematic staff performance appraisal, a commitment that made it possible the pay settlement. The findings of previous studies showed a positive correlation between PA satisfaction and job satisfaction, as well as the relationship of PA satisfaction on structural commitment and staff performance (Blau, 1999; Panggabean, 2001).

Called Personal Development and Performance Review, this process is mandatory for all academic staff, whether on a full-time or part-time employment contract and usually takes place on an annual basis. In other words, a formal yearly review has to be undertaken for each member of staff and the requirement to initiate it should, in almost all circumstances, come from the school/faculty senior management in concert with the human resources department. It is normally organized and conducted by staff in line management related to the staff member(s) being reviewed. By and large, the performance appraisal aimed at academic staff puts emphasis on several issues related to teaching, research, and administration duties. For instance, published articles and other types of published and non-published research work reflect the level of performance accomplished within the research activity. In a similar vein, performance in the teaching activity is examined through peer evaluation, students' input/feedback and data related to the course(s) taught. Table 1 shows four main general objectives as rationales for PA.

Table 1. Rationales for Performance Review

\begin{tabular}{|c|c|}
\hline General Objectives & Specific Objectives \\
\hline Developmental Use & $\begin{array}{ll}\text { - } & \text { Individual Needs } \\
\text { - } & \text { Performance Feedback } \\
\text { - } & \text { Transfers and Placements } \\
\text { - } & \text { Strengths and Development Needs }\end{array}$ \\
\hline $\begin{array}{l}\text { Administrative } \\
\text { Decisions/Uses }\end{array}$ & $\begin{array}{ll}\text { - } & \text { Salary } \\
\text { - } & \text { Promotion } \\
\text { - } & \text { Retention/Termination } \\
\text { - } & \text { Recognition } \\
\text { - } & \text { Lay Offs } \\
\text { - } & \text { Poor Performers Identification }\end{array}$ \\
\hline $\begin{array}{l}\text { Organizational } \\
\text { Maintenance }\end{array}$ & $\begin{array}{l}\text { - } \quad \text { Human Resources Planning } \\
\text { - } \quad \text { Organining Needs } \\
\text { - } \quad \text { Goal Identificational Goal Achievements } \\
\text { - } \quad \text { Human Resources Systems Evaluation } \\
\text { - } \quad \text { Reinforcement of Organizational Needs }\end{array}$ \\
\hline Documentation & $\begin{array}{l}\text { - } \text { For Human Resources Decisions } \\
\text { - Legal Requirements }\end{array}$ \\
\hline
\end{tabular}

Sources: Based on data derived from Sopiah (2016, p. 106).

\subsection{Formative and Summative Evaluations through Entrustable Professional Activities}

Within the performance evaluation process of academic staff, one needs to distinguish between formative and summative types of assessments-both are viewed as complementary forms of evaluation in the relevant literature. First, when an evaluation process is intended to improve teaching effectiveness and, as a corollary, enhance student 
learning, it is very often referred to as formative and developmental in its purpose (Chan, 2001). Focused on advancing the educational practice, this kind of appraisal results from student feedback, faculty peer reviews, direct supervisor feedback, and so forth. In these circumstances, the teaching staff evaluated tend to experience less stress and anxiety as the result is generally meant to help them reflect on their teaching practices with a view to ameliorating teaching performance. As for summative performance appraisal, it is more of a formal assessment aimed at providing clear information about the teaching staff's performance. Commonly, this review is used by the educational establishment to make various decisions pertaining to promotion, salary, and tenure.

It is important to mention that due to the effect of faculty performance appraisal on how students achieve, teaching staff find themselves under unremitting pressure to produce quality students. Yet, it is frequently admitted that the effectiveness of the process of performance assessment, particularly in the higher education sector, remains problematic. Inadequately formulated or not properly adapted to the context where they are implemented, these evaluation schemes tend to be characterized by a lack of reliable yardsticks. Also, appraisal systems driven by the primary motivation of weeding out teaching staff that are poorly performing might well have a damaging effect on the educational institution as well as these teachers. Nonetheless, this does not purport that there should be no performance culture within the institution rather this is something that ought to be fostered in order to measure the performance of academic staff. That is why educational leaders have to ensure that their staff meet academic and pedagogical quality assurances and standards of teaching through regular performance reviews (Camilleri, 2018).

When designing a scheme to evaluate teaching staff, it is deemed of crucial importance that the interests and expectations of the two main stakeholders are taken into consideration. In this respect, Dienemann and Shaffer (1992) contended that effective performance appraisal must provide useful information to both employer and employee. The employee receives information concerning organizational expectations, quality of current performance, and career development planning. Simultaneously, it provides the employer with systematic, periodic comparisons of employees to established standards. This assists in decisions regarding financial awards, and the need for counselling or even termination (p. 148). In this context, a previous study highlighted that much of employee's performance is evaluated on the perception of managers, and the biases in performance appraisal can have negative impacts on some significant structurally desired outcomes such as faculty motivations and their trust in the management (Jafri, 2017). The development of a performance appraisal arrangement requires defining the areas to be evaluated. Obviously, in higher education institutions, this encompasses those tasks entrusted to the academic staff within their respective jobs. Conventionally, there is a prevalent consensus that these duties consist of the competences of faculty based on their activities on the internal quality assurance system, especially teaching and learning tasks, which can be improved by using faculty development programs as a part of internal quality assurance system.

In 2007, the concept of Entrustable Professional Activities (EPAs) was adopted by many researchers in the medical field to operationalize competency-based medical education. As aptly put by ten Cate and Scheele, EPA can be defined as a unit of professional practice that can be fully entrusted to a trainee, as soon as he or she has demonstrated the necessary competence to execute this activity unsupervised (2007). Many results, in the medical field, have been concluded that there are perceived benefits in EPA model at training programs by increasing the number of formative assessments and feedback opportunities for trainees (Moore, et al., 2017; van Bockel, et al., 2019). A matrix-mapping approach of combining EPAs with staff competencies has been widely studied to emphasise the role of competency milestones which carried out in a day- to day practices without supervision.

The present study argues that the performance appraisal can be developed by using EPAs which can be listed to analyse the faculty members' roles, through the processes of internal quality assurance systems. A well-functioning teaching staff evaluation scheme entails a positive stance on both sides-both supervisors and employee. This attitude must take place within a framework of EPAs that not only reflect the employer's priorities and commitments, but also the employee's efforts and aspirations for professional development and career enhancement through faculty development programs of the internal quality assurance system. In other words, the success of an educational organization, such as a higher education institution, is dependent, amongst other things, on the effectiveness of teaching staff in attaining EPAs. This could possible when a performance appraisal scheme is geared towards valuing teaching staff efforts and providing them with opportunities for the professional betterment of their roles during quality assurance programs.

\section{Method}

The Delphi methodology was used to facilitate a group conversation around the appraisal system of faculty members according to their roles of internal quality assurance practices among members of preparatory year Deanship. The opinions of four groups of experts were sought with comparisons made both among and within groups to help 
determine where consensus existed answers of the following research questions:

1) How can faculty be appraised based on their roles of internal quality assurance approaches?

2) What are the expected roles of faculty according to internal quality assurance systems?

3) What are the entrustable professional activities (EPAs) for each faculty role?

4) What are the tools for each EPAs to measure the faculty's role?

\subsection{Study Design}

The study used Web-based Delphi surveys among 45 participators at PYP. The data collection process consisted of three rounds of questionnaires, administered sequentially over 16 weeks, with controlled feedback was delivered to experts between rounds for summarizing the previous round results. The study processes through Delphi rounds can be summarized as the following:

- $\quad$ Round 1: Establishing a list of expected roles that participators consider necessary for staff to develop teaching and learning, assessment, and academic advising according to the practices of internal quality assurance system. In this round, Delphi approach was used with an open-ended question to list the expected roles. Participants could complete different textboxes of roles by using QuestionPro.

- Round 2: The major themes generated in round 1 were used to establish a consensus amongst participators to identify the EPAs of each major role. Data were analyzed in this round by using the descriptive statistics (mode) to establish a consensus and essential roles of staff for internal quality assurance practices.

- Round 3: The summary results of round $1 \& 2$ were provided to panellists to reflect upon their original responses. This round aimed to make panellists aware of the range of opinions. Participants had the ability to suggest two tools can be checked to assess each listed EPA from previous rounds.

\subsection{Participants}

Based on their roles in the quality control system, 45 requests were sent to participate in the Delphi study. Participators were placed in one of four groups: (a) quality experts at the university, (b) PQAD administrators, (c) courses leaders (coordinators), and (d) members of courses development committees CDCs. Table 2 depicts the participation rate of each round.

Table 2. Summary of Expert Panel Participation for Each Round

\begin{tabular}{lccc}
\hline Rounds & Questionnaires Sent & Questionnaires Completed & \% Responses \\
\hline Round 1 & 7 & 5 & 71.4 \\
Quality Experts & 3 & 3 & 100 \\
PQAD Administrators & 10 & 8 & 80 \\
Courses Leaders & 25 & 21 & 84 \\
CDCs Members & 45 & 37 & 82.2 \\
Total & & & \\
Round 2 & 5 & 5 & 100 \\
Quality Experts & 3 & 3 & 100 \\
PQAD Administrators & 8 & 7 & 87.5 \\
Courses Leaders & 21 & 18 & 85.7 \\
CDCs Members & 37 & 33 & 89.1 \\
Total & & & \\
Round 3 & 5 & 5 & 100 \\
Quality Experts & 3 & 3 & 100 \\
PQAD Administrators & 7 & 6 & 85.7 \\
Courses Leaders & 18 & 15 & 83.3 \\
CDCs Members & 33 & 29 & 87.8 \\
Total & & & \\
\hline
\end{tabular}


Data analysis for rounds were performed by the researcher within 15 days after each survey that concluded results (i.e., descriptive statistics, measures of dispersion for each item statement). It could be reported back to experts and in conjunction with the delivery of the subsequent survey. The data were collected in 5 months, the gap between the first and last rounds was 4 months.

\section{Results}

In round 1, 37 expert panellists, classified in one of the four subgroups of quality experts ( $\mathrm{n}=5)$, PQAD administrators $(n=3)$, courses leaders $(n=8)$, CDCs Members $(n=21)$, responded to the question, "what are the expected roles of faculty according to PQAD program implementation?". There were 37 essay responses to this question. The responses were collated, combined, and compressed to generate 26 item statements that were then categorized into 4 major roles by carrying out a content analysis of the experts' responses and descriptions from literature according to the practices of quality assurance and PQAD program implementation at PYP. The reported roles can be discussed in more details as the following:

- Instructor: in this role, the participants reported many expected tasks for teaching and learning activities, e.g. using effective strategies for active learning during lectures or practical sessions, provide constructive feedback and clear instructions to the students, and allocate time to students during classes to ask questions and discuss their ideas or present their work.

- Planner: the participants determined many tasks relevant to the faculty role as a course designer to prepare the learning outcomes, sessions plans, active learning modules or activities, and the assessment plan. Moreover, the preparation of their action plan to develop teaching and learning performance.

- Assessor: three main roles were reported by the experts to determine the faculty role as an assessor namely, plan and execute the written exams, assess performance based on rubrics, and develop exam items in different formats, e.g. A-type, R-type, script concordance.

- Mentor: this role includes tasks of faculty which helps their students to feel cared and supported by handling issues related to registration at courses and providing effective academic advice. For each role, participants gave definitions comprised of EPAs.

The list of roles and tasks, aggregated from the open-ended question in round 1, was shared with the panellists for round 2 survey. The summarized results of the first round were also attached namely, percentage of agreement/disagreement with each role and tasks. Participants answered the questionnaire by using the 5-point Likert scale to measure the consensus of 14 tasks for all roles. Table 3 depicts the means and standard deviations of these roles.

Table 3. Means and Standard Deviations for Roles

\begin{tabular}{lllllllll}
\hline \multirow{2}{*}{ Roles } & \multicolumn{2}{c}{ Quality Experts } & \multicolumn{2}{l}{ PQAD Administrators } & \multicolumn{2}{c}{ Courses Leaders } & \multicolumn{2}{c}{ CDCs Members } \\
& $\mathrm{M}$ & $\mathrm{SD}$ & $\mathrm{M}$ & $\mathrm{SD}$ & $\mathrm{M}$ & $\mathrm{SD}$ & $\mathrm{M}$ & $\mathrm{SD}$ \\
\hline Instructor (4 items) & 3.15 & 0.97 & 3.60 & 1.18 & 4.3 & 1.3 & 4.75 & 1.45 \\
Planner (5 items) & 4.85 & 0.54 & 4.92 & 1.36 & 3.2 & 0.73 & 3.57 & 0.43 \\
Assessor (3 items) & 3.86 & 1.22 & 5.32 & 1.07 & 4.66 & 1.70 & 4.55 & 1.41 \\
Mentor (2 items) & 2.34 & 0.86 & 3.25 & 0.85 & 2.75 & 0.93 & 3.52 & 1.73
\end{tabular}

In round 3, by using interquartile range (IQR) and standard deviation, participants reanswered each task that did not meet consensus between them. According to Rayens and Hahn (2000), IQR of 1 or less was a suitable consensus indicator for a 5-point Likert scale. IQR values remained the same for $57 \%(\mathrm{n}=8)$, increased for $29 \%(\mathrm{n}=4)$, and decreased for $14 \%(n=2)$ of the tasks between rounds. Standard deviation values decreased for $10(71 \%)$ of the items, increased by 4 (29\%) from round 2 to round 3. Participants have the opportunity to write definitions comprised of EPAs for each role. Moreover, they could suggest the tools or activities of each EPA be assessed based on the requirements of the internal quality assurance system. They have demonstrated the necessary competence to execute this activity unsupervised. 


\section{Discussion}

The results establish consensus on the tools of performance appraisal of faculty members based on entrustable activities of their roles in quality assurance system. Through three stages of Delphi study, the experts have suggested 18 tools or activities relevant to 14 professional practices that can be fully entrusted to faculty through processes and requirements of the internal quality assurance system. Table 4 shows the suggested EPAs for each role and how to be assessed by using several tools of the program of internal quality control system QADP.

Table 4. EPAs or Skills-set of Faculty Members Based on IQA.

\begin{tabular}{|c|c|c|}
\hline Role & EPAs & To be assessed via checking... \\
\hline $\begin{array}{l}\text { As an } \\
\text { Instructor }\end{array}$ & $\begin{array}{l}\text { - To act as an effective teacher at lectures. } \\
\text { - To act as an effective demonstrator at a } \\
\text { practical session. } \\
\text { - To provide feedback on students' } \\
\text { performance. } \\
\text { - To apply effective strategies for classroom } \\
\text { management. }\end{array}$ & $\begin{array}{l}\text { - Faculty peer reviews. } \\
\text { - Post-session Reflection. } \\
\text { - Students' surveys of learning skills. } \\
\text { - Students' achievements and grades. } \\
\text { - Teaching effectiveness evaluation } \\
\text { survey. }\end{array}$ \\
\hline $\begin{array}{l}\text { As a } \\
\text { Planner }\end{array}$ & $\begin{array}{l}\text { - To set clear learning outcomes at the course } \\
\text { and session levels. } \\
\text { - To develop session plans. } \\
\text { - To plan active learning modules. } \\
\text { - To plan the assessment at the course level. } \\
\text { - To set and monitor his/her own Individual } \\
\text { Development Plan (IDP). }\end{array}$ & $\begin{array}{l}\text { - Course Outcome Trees. } \\
\text { - Session plans. } \\
\text { - Active learning modules. } \\
\text { - Assessment plans. } \\
\text { - Course blueprints. } \\
\text { - Individual Development Plans. }\end{array}$ \\
\hline $\begin{array}{l}\text { As an } \\
\text { Assessor }\end{array}$ & $\begin{array}{l}\text { - To plan and execute written exams. } \\
\text { - To assess performance based on rubrics. } \\
\text { - To develop exam items in different formats, } \\
\text { e.g. A-type, R-type, Script Concordance, ...etc. }\end{array}$ & $\begin{array}{l}\text { - Exam blueprints. } \\
\text { - Quality of rubrics by faculty. } \\
\text { - Item analysis } \\
\text { - Inter-rater reliability. } \\
\text { - Exam reports. }\end{array}$ \\
\hline $\begin{array}{l}\text { As a } \\
\text { Mentor }\end{array}$ & $\begin{array}{l}\text { - To handle issues related to the registration } \\
\text { of students at courses. } \\
\text { - To offer effective academic advising. }\end{array}$ & $\begin{array}{l}\text { - Monitor students' registration. } \\
\text { - Students' feedback on advising } \\
\text { services. }\end{array}$ \\
\hline
\end{tabular}

The findings emphasize, through comments of the experts, the importance of EPAs as evaluation instruments meant to enhance creativity, emotional provision, and commitment of internal quality assurance activities. In the behavioural descriptions of activities, the experts suggest evidence of quality indicators for teaching, assessment, and advising roles which can help higher education institutions in increasing the proficiency and objectivity of the management of human resources. These results are in agreement with previous studies (Favreau et al., 2017; Jafri, 2017) in pointing out the dimensions for core of EPA faculty development namely, observation skills in authentic settings, coaching skills, reflection skills or self-assessment, and peer guidance skills developed through a community of practice. Moreover, it provides several tools to help the educational institutions in minimizing biases in the performance appraisal system of faculty especially in universities where performance less verifiable and measurable by using 360-degrees feedback evaluation. This type of evaluation would motivate the faculty to show their capabilities in several responsibilities and excel in the performance appraisal (Arnăutu, 2015; Shaikh et al., 2008; Kumari et al., 2015). Additionally, the suggested EPAs can be used to demonstrate the necessary competences to execute these activities unsupervised, and it can be also used to plan faculty development programs based on actual needs or performance gaps of faculty members at three levels: individual, departmental, and program or college. 


\section{Conclusion}

The study has highlighted a list of practical EPAs to develop the competency-based faculty appraisal. The suggested activities provide a framework that can be expanded to a core set of skills to suit the required practice of faculty profile for the internal processes of quality control. As a result, using EPAs necessitates multifaceted appraisal system and needs to be more continuous and frequent. The findings have both applied and theoretical implementations. The insights of the study collected some required approaches in causing improvement in faculty engagement with their work, and their trust in management. Theoretically, the study will extend enhancement the literature of employee motivation and workplace trust from the perspective of prejudices in performance appraisal. The developed tools, in the current study, had been suggested based on what could be extracted from the internal quality assurance system at IAEU. As such, the study has certain limitations especially taking into consideration that establishing comprehensive entrustment activities for performance appraisal of faculty members warrants further studies according to the quality processes and procedures of the institutions. The educational bodies can consider re-establishing instruments to include specific tools according to the adapted quality system. More required researches need to take into consideration the new strategies that combine the best of both quantitative and qualitative schemes and purposely include context as a key constituent of the study.

\section{References}

Arnăutu, E., \& Panc, I. (2015). Evaluation criteria for performance appraisal of faculty members. Procedia - Social and Behavioral Sciences, 203, 386-392. https://doi.org/10.1016/j.sbspro.2015.08.313

Bartol, K. M., \& Martin, D. C. (1998). Management (3rd ed.). New York: McGraw-Hill Companies.

Bradley, H. (1992). Getting the Best out of Appraisal'. Journal of the Educational Research Network of Northern Ireland, 6, 127-135.

Blau, G. (1999). Testing the longitudinal impact of work variables and performance appraisal satisfaction on subsequent overall job satisfaction. Human Relations, 52(8), 1099-1113. https://doi.org/10.1177/001872679905200806

Camilleri, Mark and Camilleri, Adriana, The Performance Management and Appraisal in Higher Education (September 5, 2018). Camilleri, M.A. \& Camilleri, A.C. (2018). The Performance Management and Appraisal in Higher Education. In Cooper, C. Driving Productivity in Uncertain and Challenging Times. (University of the West of England, 5th September). British Academy of Management, UK., Available at SSRN: https://ssrn.com/abstract=3238664

Cardoso, S., Rosa, M. J., Videira, P., \& Amaral, A. (2018;2019;). Internal quality assurance: A new culture or added bureaucracy? Assessment and Evaluation in Higher Education, 44(2), 249-262. https://doi.org/10.1080/02602938.2018.1494818

Caruth, D. L., Caruth, G. D., \& Pane, S. S. (2008). Staffing the Contemporary Organization: A Guide to Planning, Recruiting, and Selecting for Human Resource Professionals: A Guide to Planning, Recruiting. ABC-CLIO.

Chan, K. (2001). The difficulties and dilemma of constructing a model for teacher evaluation in higher education. Higher Education Management, 13(1), 93-111.

Deb, T. (2006). Strategic Approach to Human Resource Management: Concept, Tools \& Application. New Delhi: Atlantic Publishers and Distributors.

Dienemann, J., \& Shaffer, C. (1992). Faculty performance appraisal systems: Procedures and criteria. Journal of Professional Nursing, 8(3), 148-154. https://doi.org/10.1016/8755-7223(92)90024-S

Favreau, M. A., Tewksbury, L., Lupi, C., Cutrer, W. B., Jokela, J. A., Yarris, L. M., \& AAMC Core Entrustable Professional Activities for Entering Residency Faculty Development Concept Group. (2017; 2016;). Constructing a shared mental model for faculty development for the core entrustable professional activities for entering residency. Academic Medicine, 92(6), 759-764. https://doi.org/10.1097/ACM.0000000000001511

Fletcher, C. (2001). Performance appraisal and management: The developing research agenda. Journal of Occupational and Organizational Psychology, 74(4), 473-487. https://doi.org/10.1348/096317901167488

Galle, J. (2009). Evaluating faculty performance: A practical guide to assessing teaching, research, and service edited by Peter Seldin.UK: Blackwell Publishing Ltd. https://doi.org/10.1111/j.1467-9647.2009.00514.x

Jafri, M. H. (2017). performance appraisal errors and its influence on employee engagement and workplace trust: A study on university faculties in Bhutan. Prestige International Journal of Management and Research, 10(2), 19-25.

Published by Sciedu Press 
Kumari, S., Patil, Y., \& Rani, A. (2015). Emerging role conflict among female faculty members in institutes. Age, 20(30), 22.

Marsh, H. W. (1987). Students' evaluations of university teaching: Research findings, methodological issues, and directions for future research. International Journal of Educational Research, 11(3), 253-388. https://doi.org/10.1016/0883-0355(87)90001-2

Mathis, R. L., \& Jackson, J. H. (2008). Human Resource Management (12th ed.). Mason, Ohio: South-Western Publishing Co. Retrieved from: https://core.ac.uk/download/pdf/33797590.pdf

Moore, D., Young, C. J., \& Hong, J. (2017). Implementing entrustable professional activities: The yellow brick road towards competency-based training? ANZ Journal of Surgery, 87(12), 1001-1005. https://doi.org/10.1111/ans.14120

Panggabean, M. S. (2001). Impact of perceived justice in performance appraisal on work attitudes and performance.

Rayens, M. K., \& Hahn, E. J. (2016;2000;). Building consensus using the policy Delphi method. Policy, Politics \& Nursing Practice, 1(4), 308-315. https://doi.org/10.1177/152715440000100409

Rector, J. L. (2009). Faculty Perceptions of Faculty Evaluation Programs at Selected Private Colleges/Universities in the Southeast United States. (Unpublished doctoral dissertation). The University of Tennessee, Chattanooga.

Richardson, J. T. E. (2005). Instruments for obtaining student feedback: A review of the literature. Assessment \& Evaluation in Higher Education, 30(4), 387-415. https://doi.org/10.1080/02602930500099193

Schuler, R.S., Beutal, N. J., \& Youngblood, S. A. (1989). Effective Personnel Management (3rd ed.). New York: West Publishing Co.

Shaikh, N., Kumari, S., \& Kasat, K. (2018). Exploring E-Governance of Faculty Evaluation System: Using a Total Interpretive Structural Modeling Approach. Journal of Cases on Information Technology (JCIT), 20(3), 36-47. doi:10.4018/JCIT.2018070103

Sonnentag, S., \& Frese, M. (2002). Performance concepts and performance theory, 1-25. Chichester, UK: John Wiley \& Sons, Ltd. https://doi.org/10.1002/0470013419.ch1

Sopiah, S. (2016). The relationship between performance appraisal and job performance. International Journal of Academic Research in Business and Social Sciences, 6(6), 104-115 https://doi.org/10.6007/IJARBSS/v6-i6/2182

Staffing the contemporary organization; a guide to planning, recruiting, and selecting for human resource professionals, 3d ed (2009). Portland: Ringgold, Inc

Tavares, O., Sin, C., Videira, P., \& Amaral, A. (2017). Academics' perceptions of the impact of internal quality assurance on teaching and learning. Assessment \& Evaluation in Higher Education, 42(8), 1293-1305. https://doi.org/10.1080/02602938.2016.1262326

Ten Cate, O., \& Scheele, F. (2007). Competency-based postgraduate training: Can we bridge the gap between theory and clinical practice? Academic Medicine: Journal of the Association of American Medical Colleges, 82(6), 542-547. https://dog.org/10.1097/ACM.0b013e31805559c7

Van Bockel, E. A. P., Walstock, P. A., van Mook, W. N. K. A., Arbous, M. S., Tepaske, R., van Hemel, T. J. D., \& Tulleken, J. E. (2019). Entrustable professional activities (EPAs) for postgraduate competency based intensive care medicine training in the Netherlands: The next step towards excellence in intensive care medicine training. Journal of Critical Care, 54, 261-267. https://doi.org/10.1016/j.jcrc.2019.09.012

\section{Copyrights}

Copyright for this article is retained by the author(s), with first publication rights granted to the journal.

This is an open-access article distributed under the terms and conditions of the Creative Commons Attribution license (http://creativecommons.org/licenses/by/4.0/). 